\title{
DIGITAL MEDIA SOSIAL UNTUK MEMPROMOSIKAN “GEBLEK YU LASTRI" DI DESA NANGGULAN KULON PROGO PADA MASA PANDEMI COVID 19
}

\author{
Esty Wulandari, Bedjo Riyanto, Jazuli Abdin Munib, Ahmad Adib, \\ M.Suharto \\ Prodi Desain Komunikasi Visual, FSRD, Universitas Sebelas Maret \\ Jl. Ir. Sutami No. 36A, Kentingan Surakarta 57126. Telp 0271-646994 \\ Email estywulandari@staff.uns.ac.id, bedjoriyanto@staff.uns.ac.id, \\ jazuliabdin@staff.uns.ac.id,ahmadadib@staff.uns.ac.id,mohamadsuharto@staff.uns.ac.id
}

\begin{abstract}
Abstrak
Pandemi covid 19 memberi dampak bagi semua aspek termasuk bidang Usaha Mikro, termasuk penjualan menurun,permodalan, pesanan menurun. Dari sisi supply banyak UMKM mengalami pengurangan aktivitas dikarenakan adanya kebijakan pembatasan interaksi sosial yang berujung pada terhentinya proses produksi. Dari sisi demand, berkurangnya permintaan atas barang yang dijual mengakibatkan banyak yang tidak mendapatkan keuntungan. Terganggunya usaha mikro akan berakibat pada masyarakat pemilik usaha rumahan, mengalami kehilangan pendapatan.Untuk mengatasi hal tersebut, maka dilakukan bentuk ekosistem digital, digitalisasi dilakukan dengan melakukan proses pemasaran secara online. Tujuan kegiatan ini memberi pelatihan dan pendampingan dalam strategi visual branding dengan membuat logo, merek, kemasan membuat promosi melalui Instagram untuk Geblek Yu lastri. Metode yang digunakan adalah pelatihan serta pendampingan dengan pendekatan partisipatif dan kolaboratif dalam pengembangan inovasi pemilik Geblek. Kedua, memberikan pengarahan, bimbingan dan pembinaan kepada pemilik usaha Geblek agar bisa dikembangkan secara lebih professional. Misalnya dalam hal standarisasi mutu, kualitas dan higienitas produk.

Hasil dari kegiatan PKM CSR ini adanya kemasan, logo serta desain instagram untuk Geblek Yu lastri. Hasil dari kegiatan PKM CSR ini meningkatkan jumlah penjualan geblek mentah siap goreng Yu lastri menjadi 10 bungkus/ hari, menjadi lebih dikenal di masyarakat sekitar dan bisa memasarkan secara online, serta memperluas pemasaran di daerah Kab Kulon Progo, Yogyakarta. Dampak Digital sosial media yang dilakukan dengan membuat visual branding Geblek Yu Lastri dan sudah membuat promosi untuk diposting di Instagram. Promosi yang dilakukan melalui Media Sosial, sebagai makanan khas tradisional dan sebagai Oleh-oleh Khas Kab.Kulon Progo bisa bertahan untuk dipasarkan. Hasil evaluasi dari pengabdian masyarakat ini,membuat pemilik usaha geblek Yulastri bisa mempromosikan produknya melalui media sosial instagram maupun Whatsapp, untuk mendukung pemasaran online.
\end{abstract}

Kata Kunci : Media Sosial Digital Media, Visual Branding, Geblek 


\section{PENDAHULUAN}

Pandemi covid 19 memberi dampak bagi semua aspek termasuk bidang Usaha Mikro, termasuk penjualan menurun,permodalan, pesanan menurun. Dari sisi supply banyak UMKM mengalami pengurangan aktivitas dikarenakan adanya kebijakan pembatasan interaksi sosial yang berujung pada terhentinya proses produksi. Dari sisi demand, berkurangnya permintaan atas barang yang dijual mengakibatkan banyak yang tidak mendapatkan keuntungan. Terganggunya usaha mikro akan berakibat pada masyarakat pemilik usaha rumahan, mengalami kehilangan pendapatan.Untuk mengatasi hal tersebut, maka dilakukan bentuk ekosistem digital, digitalisasi dilakukan dengan melakukan proses pemasaran secara online, apalagi dimasa pandemi ini yang menghendaki pembatasan interaksi sosial secara langsung.

Tujuan dari Kegiatan PKM CSR ini memberikan pendampingan serta pelatihan tentang merek, visual branding, kemasar geblek, serta promosi online menggunakan Instagram kepada pemilik geblek Yu lastri.

Manfaat dari kegiatan ini, mengenalkan media sosial instagram untuk dipakai sebagai media promosi serta untuk melaksanakan pemasaran secara online. Serta meningkatkan nilai jual geblek dengan memberikan merek, serta membuat kemasan yang menarik untuk geblek yu lastri ini. Merek dipandang penting karena merek adalah sebuah nama, istilah, tanda, simbol atau desain atau kombinasi semuanya yang dimaksudkan untuk mengidentifikasi produk/jasa dengan yang lain dan untuk mendifferensiasikan mereka dari persaingan.(Christiana, $200: 194)$

Brandng adalah upaya untuk membangun image tentang suatu merk produk atau jasa di benak konsumen. Branding digunakan untuk membangun citra produk, dan dikomunikasikan melalui media.Suatu brand/merk yang sudah memiliki perceived quality yang kuat bahkan mampu meyakinkan konsumennya. (Arief Budiman 2008 : 54)

Geblek merupakan makanan khas Kulon
Progo, terbuat dari Pati singkong yang masih basah.Geblek berwarna putih dan bentuknya menyerupai angka delapan. Rasa Geblek khas kulon progo ini asin dan sangat gurih, sekaligus kenyal, dan disajikan selagi hangat. Geblek jika sudah dingin akan terasa kenyal. Geblek biasanya disajikan dengan tempe besengek yaitu tempe benguk yang lembut dan kuat rasa gurih santan kelapa. Besengek dimasak dengan menggunakan kayu bakar untuk menghasilkan tempe yang lembut. Geblek Kulon Progo sering ditemui di pasar tradisional,ditempat wisata maupun dijual dipinggir jalan di daerah Kulon Progo. Cara pembuatan

1. Tujuan Program Kemitraan

Beberapa hal yang menjadi tujuan prioritas adalah sebagai berikut:

a. Membuat inovasi desain kemasan geblek mentah (siap goreng)

b. Membuat identitas merek atau logo yang menarik untuk geblek mentah mentah (siap goreng)

c. Membuat Media promosinya

\section{METODE}

\section{a. Tempat dan Waktu}

Program Pengabdian masyarakat ini dilakukan di Desa Nanggulan, Kab.Kulon Progo dan dimulai dari bulan Agusus s/d September 2020. Kegiatan ini mengambil subyek pemilik Geblek Yu Lastri

\section{b. Metode Pendekatan Pengabdian}

Metode yang digunakan dalam kegiatan ini dengan menerapkan observasi dan wawancara. Observasi dilakukan dengan melihat proses pembuatan geblek gurih, proses jual beli antara pemilik usaha dengan pembeli sehingga dapat diketahui sejauhmana kelebihan dan kekurangan pemilik usaha dalam memasarkan produk geblek ini. Melihat beberapa kemasan yang belum dikemas dengan menarik tapi hanya menggunakan tempat plastik yang seadanya saja, serta beberapa media promosi yang belum ada. Serta, keinginan pembeli untuk membeli geblek siap goreng yang terkendala dalam hal kemasan yang kurang 
menarik. Padahal makanan khas tradisional kab. Kulon progo akan selalu dicari pembeli sebagai oleh-oleh, terutama pada saat menjelang lebaran, libur sekolah maupun pada libur hari raya nasional lainya.

Pendekatan yang digunakan dalam pengabdian ini dengan pendekatan kolaboratif, antara peserta dan tim pengabdi secara kolaboratif bersama-sama saling mewujudkan program pengembangan kemasan geblek gurih ini sebagai oleh-oleh makanan khas tradisional khas Kab.Kulon Progo, agar pemasaran dapat berjalan dengan baik sehinga dengan menggunakan metode ini diharapkan lebih maksimal.

\section{c. Kegiatan yang telah dilakukan}

Kegiatan yang dilakukan dengan bentuk kegiatan sebagai berikut :

1. Pembuatan desain kemasan geblek Yu Lastri

2. Pembuatan desain promosi untuk geblek $\mathrm{Yu}$ lastri melalui instagram

\section{d. Partisipasi Mitra}

Agar kegiatan pengabdian dapat berjalan dengan lancar, maka mitra bisa bekerjasama dalam hal :

1. Menyediakan sarana ruang untuk pelatihan

2. Bersedia mengikuti pelatihan

3. Mengatur jadwal pelatihan

Evaluasi pelaksanaan program dan keberlanjutan program setelah selesai kegiatan Program Kemitraan Masyarakat (PKM) dilaksanakan. Pendekatan yang digunakan dalam pengabdian ini dengan pendekatan kolaboratif, antara peserta dan tim pengabdi secara kolaboratif bersamasama saling mewujudkan program pengembangan kemasan geblek gurih ini sebagai oleh-oleh makanan khas tradisional khas Kab.Kulon Progo, agar pemasaran dapat berjalan dengan baik sehinga dengan menggunakan metode ini diharapkan lebih maksimal.

\section{HASIL DAN PEMBAHASAN}

\section{PENDAMPINGAN VISUAL BRANDING DENGAN MEMBUAT LOGO DAN DESAIN KEMASAN}

Membuat desain kemasan makanan sangat penting karena adanya perpadauan kreativitas dan fungsi untuk melindungi suatu produk yan dibuat secara menarik. Pada saat membuat desain kemasan harus mengetahui pola pikir konsumen termasuk kemasan yang seperti apa yang dibutuhkan dan diinginkan oleh konsumen. Begitu banyak aspek yang dipikirkan dan harus bisa diterima konsumen dalam membuat desain kemasan yang bisa menampilkan keunggulan produk tsb.

Jika terkait dengan bidang pemasaran, maka kemasan bisa menjadi sarana untuk promosi. Selain sebagai media promosi, maka kemasan juga sebagai sarana untuk memasarkan suatu produk sehingga sesuai apa yang menjadi dengan kebutuhan dan keinginan konsumen. Didalam Komunikasi Pemasaran, kemasan memiliki peran untuk mengkomunikasikan keunggulan produk kepada konsumen, mengangkat citra suatu produk serta meningkatkan penjualan. Adapun kemasan harus diperhatikan oleh produsen karena kemasan berfungsi sebagai berikut :

a. Mewadahi produk selama distribusi dari produsen hingga sampai ke tangan konsumen agar lebih aman, dan terjaga kualitas produknya.

b. Melindungi dan mengawetkan produk seperti melindungi dari sinar 
matahari, panas, kelembapan udara, oksigen, benturan, kontaminasi dan kotoran dan mikroba yang dapat merusak mutu produk

c. Sebagai identitias produk dalam hal ini kemasan dapat digunakan sebagai alat komunikasi dan informasi kepada konsumen melalui label yang terdapat pada kemasan. (Thomas S.Kaitu, $2014:$ 7)

d. Fungsi tambahan dari kemasan akan semakin meningkat dengan adanya persaingan dibidang industri makanan. Fungsi tambahan ini justru lebih ditonjolkan, sehingga penampilan kemasan harus betulbetul menarik bagi calon pembeli, dengan cara membuat :

Kemasan yang berwarna dan mengkilat sehingga menarik dan berkesan mewah, dapat mengesankan berisi produk yang bermutu dan berkualitas, desain teknik dari wadahnya memudahkan pemakai serta teknik wadahnya bisa lebih tahan lama dan dibuat dengan teknik mutakhir serta mengikuti perkembangan zaman.

Karena pentingnya kemasan pada makanan yaitu memiliki fungsi melindungi produk, serta kemasan dapat digunakan sebagai identitas produk maka perlu dirancang kemasan yang menarik. Meskipun geblek hanya produk makanan lokal dan diproduksi UMKM tapi perlu dibuat pula identitas dan logo untuk ini.Karena sebagai makanan lokal biasanya para wisatawan banyak mencari makanan khas ini sebagai oleh-oleh.Sehingga,untuk membedakan

Visual Branding yang menjadi Identitas produk ini sangat penting, didalam komunikasi pemasaran keberhasilan visual branding menentukan apakan produk ini diterima oleh konsumen atau tidak, dan berakibat pula dengan penjualan. Kemasan yang menarik sangat penting karena sebagai pembeda dan sebagai media promosi. Karena dengan adanya kemasan menambah daya tarik pembeli maka dalam membeli produk ini.

Dari hasil pengamatan dan wawancara dengan pemilik usaha dan geblek Yu Lastri, belum adanya kemasan yang menarik untuk wadah geblek mentah. Padahal geblek mentah selalu dicari konsumen untuk oleh-oleh para wisatawan. Karena geblek mentah akan lebih tahan lama daripada geblek yang sudah goreng. Geblek mentah ini bisa bertahan selama 2 hari dalam suhu ruang, dan bertahan selama 5 hari jika disimpan dikulkas

Dalam membuat desain kemasan produk makanan yaitu geblek, harus dibuat dengan mencantumkan logo, PIRT serta komposisi bahan dari geblek, serta alamat dan bisa dihubungi jika konsumen membutuhkan geblek dalam jumlah banyak.

B. Pembuatan desain logo untuk geblek

1. Logo Untuk Geblek Yu Lastri

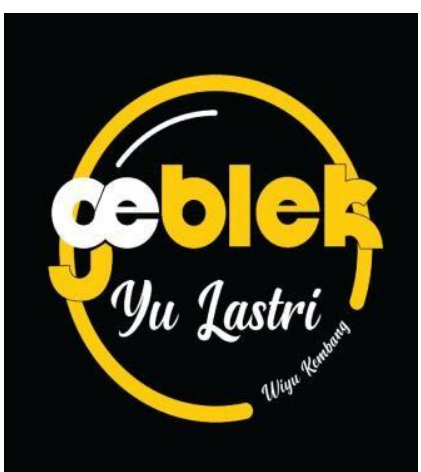

Gambar 1 : Logo Geblek Yu Lastri

Logo untuk geblek $\mathrm{Yu}$ Lastri ini menggunakan warna hitam, warna putih dan kuning dengan menggunakan typografi dari bentuk geblek itu sendiri. Karena geblek merupakan makanan yang terbuat dari pati singkong yang menyerupai angka delapan

Serta warna putih geblek juga digunakan sebagai logo sehingga terbentuk Logo Type Geblek Mbak Lastri yang berasal dari daerah Wiyu Kembang, Nanggulan, Kab. Kulon Progo. Geblek Yu Lastri diambil dari nama si pemilik usaha.

1. Desain kemasan untuk geblek yu lastri 


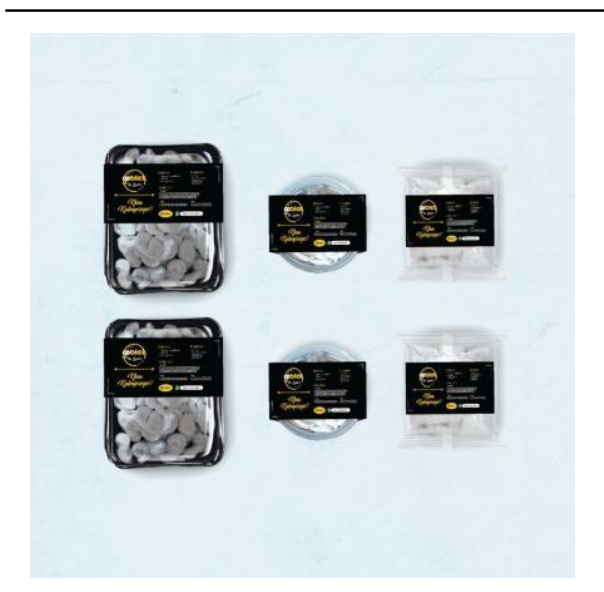

Kemasan ini menggunakan bahan styrofoam sebagai wadah geblek dan ditutup dengan menggunakan plastik dan diberi label diatasnya sehingga kemasan ini dibuat jika pembeli menginginkan geblek mentah untuk digoreng dirumah. Dengan kemasan yang menarik ini maka akan terlihat bermutu dan berkualitas, dan meningkatkan image produk geblek itu sendiri. Nantinya geblek ini akan dikemas sesuai dengan permintaan konsumen, tersedia dalam ukuran $250 \mathrm{gr}$,

500 gr sesuai dengan keinginan konsumen dan dijual dengan range harga untuk @100 gr seharga Rp 15.000 dan @ 250 gr dijual dengan harga Rp 25.000. Supaya lebih awet dan tahan lama produk ini bisa disimpan di kulkas selam 5 hari.

Membuat Promosi Untuk Diupload di Instagram

Semakin banyaknya pengguna media sosial oleh hampir semua kalangan masyarakat di era digital ini, apalagi pada saat Pandemi Covid 19 ini, digital ekonomi menjadi salah satu cara untuk menggerakan UMKM untuk terus berlanjut. Salah satu hal yang bisa dilaksanakan oleh UMKM untuk terus berjalan adalah dengan menggunakan media sosial, salah satunya menggunakan Instagram Bisnis. Pelaku UMKM menggunakan media sosial sebagai cara untuk menjual serta mempromosikan produknya. Instagram bisnis dipakai dimana akun kita diubah dan disetting untuk keperluan promosi bisnis
- $\quad$ Foto Produk untuk diposting Instagram Yu lastri (geblek yang sudah digoreng)

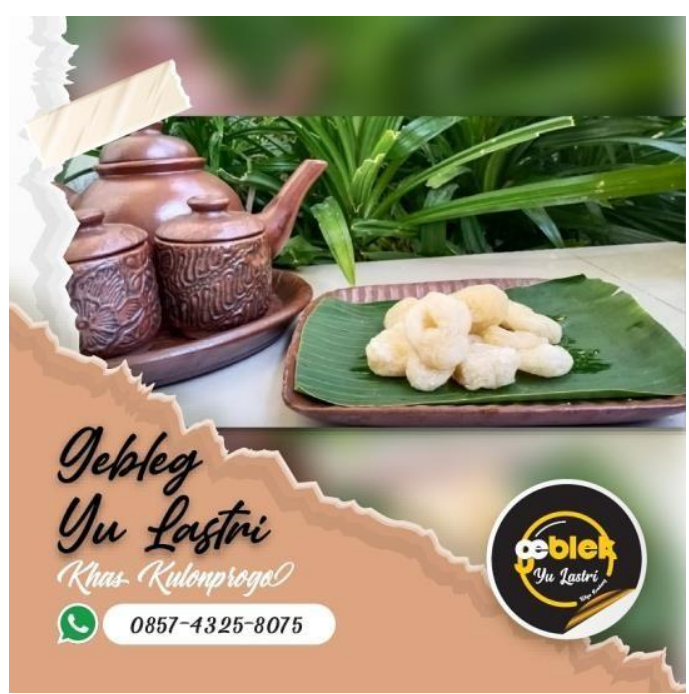

Gambar 2 : Geblek yang sudah digoreng

- Instagram geblek Yu lastri

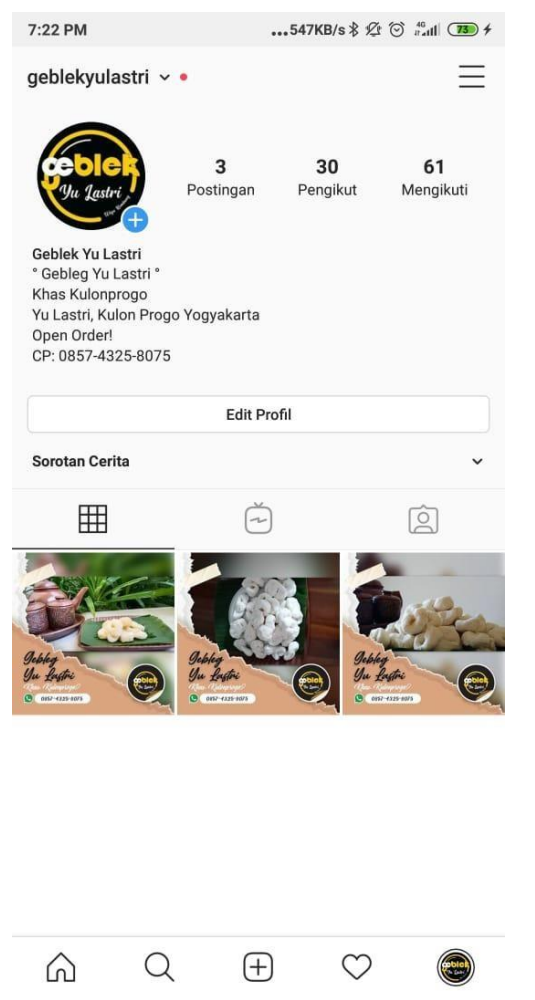

Gambar 3 : instagram produk Geblek

Yu Lastri 
- Desain posting Instagram Yu lastri (geblek mentah belum digoreng)

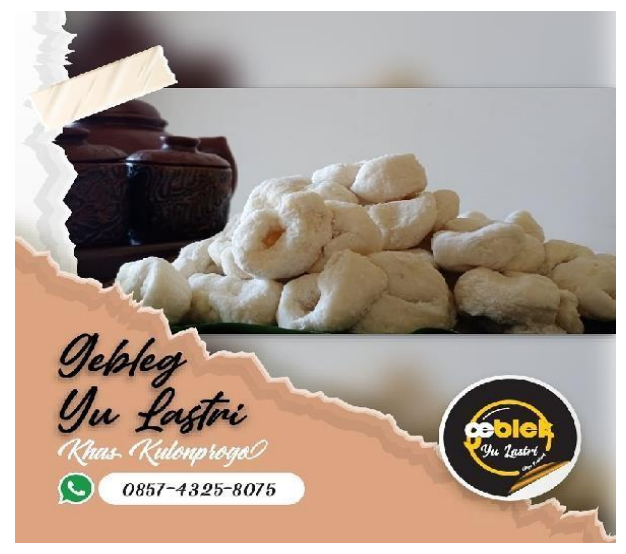

\section{Kesimpulan}

Kegiatan ini sudah dilaksanakan pada bulan agustus hingga september 2020 . Geblek Yu lastri bisa meningkatkan penjualan produknya menjadi 10 bungkus geblek per hari, yang dilakukan secara online. Dari pendapat konsumen mereka membeli geblek karena adanya informasi atau promosi yang disampaikan melalui media sosial instagram dan juga whatsapp. Geblek $\mathrm{Yu}$ lastri dengan adanya kemasan juga meningkatkan nilai produknya, dan mencoba untuk memasarkan dengan menjual produk ini di restoran yang ada di daerah Nanggulan, seperti Restoran Kopi Klothok dan Restoran Ampirono.

Kemasan untuk geblek yu lastri juga mempunyai fungsi sebagai daya tarik konsumen, karena konsumen lebih tertarik untuk membelinya karena ingin mencoba, atau untuk dikonsumsi. Meskipun geblek merupakan makanan khas tradisional namun sudah dibuat kemasan yang menarik Para wisatawan selalu mencari makanan khas tradisional untuk oleh-oleh. Karena geblek sudah terbiasa dikonsumsi dengan cara sudah digoreng terlebih dahulu lalu dijual maka ada pula konsumen yang membeli dalam bentuk geblek mentah siap goreng, yang nantinya dibeli sebagai oleh- oleh.
Keberlanjutan program PKM CSR ini yaitu promosi melalui digital sosial media diharapkan mampu membuat pelaku usaha geblek yu lastri ini bisa bertahan dan menjual produknya secara online.

\section{REFERENSI}

Christiana Ariadne Sekar Sari. Teknik Mengelola Produk\&Merek : Konsep dan Aplikasi pada Fast Moving Consumer Goods, 2017.PT.Gramedia Pustaka Utama: Jakarta,2017

Kottler dan Keller.Manajemen Pemasaran Jilid I Edisi ke 13. 2009. Jakarta : Erlangga

Klimchuk, Marianne dan Sandra A Krasovec. Desain Kemasan. 2006.Jakarta : Erlangga

M Arif Budiman. Jualan Ide Segar. 2008.Galang Press. : Yogyakarta

Neumeier, Marty.The Brand Gap: How to Bridge The Distance Between Business Strategy and design.2005.English.: eachpit Pre 
